\title{
The Competency in Using Smartphones of the Homebound Older Adult
}

\author{
https://doi.org/10.3991/ijim.v15i09.20885 \\ Patana Duangpatra $\left.{ }^{(}\right)$, Bunchoo Bunlikhitsiri, Peera Wongupparaj \\ Burapha University, Saen Suk, Thailand \\ jammycray@gmail.com
}

\begin{abstract}
Smartphones are widely accessed by all genders, ages, and statuses with the increasing use rate of older adults. When people grow up to older adults, they meet physical declines such as blurred vision, tremor in hands, and arms, slowness of movement, or postural of a humpback. These age-related conditions affect how they live and use the smartphone. However, some seldom go out for older adults' activities due to their physical impairment and diseases. They might have lower competencies than normal older adults. In this article, the test was conducted on 26 homebound older adults. The current investigation was concerned with their competencies of vision, hearing, touching, and memorizing to find appropriate average results for them. We found the scores value regarding font size, color contrast, icon size, a touching point on each button on the screen, keyboard's size, scrolling area, etc., which they can perform effectively on the smartphone. The main findings render a significant and unique contribution to the design community to use it as a guideline or standard for every designer who wants to design assisted technology by using a touch screen interface for homebound older adults to conveniently access and efficiently use. Further, it also helps to improve the quality of life among older adults.
\end{abstract}

Keywords - Interaction, User interface, Smartphone, Aging, Older Adult

\section{Introduction}

We are currently in a digital society where digital media and devices are widespread to all areas of almost all genders and ages[32]. According to National Statistical Office, the number of older adults in Thailand increase every year in line with the increasing rate of their smartphone uses. Among these baby boomer generation, their average usage rate of the internet is 10 hours per day, close to Thai people at 10 hours 22 minutes per day, with the average growth rate at $14.5 \%$ per year[1].

Some older adults are homebound older adults who stay home without preference for outdoor activities because they may have health problems or some burdens at home such as osteoarthritis, big legs, blurred vision, rarely money, or need to take care of their parents. The older adults who have physical impairments typically meet the difficulties of using smartphones because they have more difficulty seeing, moving, per- 
ceiving, and slower responses. Moreover, hand mobility in association with vision becomes slower and difficult to touch the screen, and they might have lower competencies than other normal older adults. All of this problem affects digital devices' uses, concerning typography[33],font size[32], color contrast[43], icons, and icon interpretation, which is on the smartphone screen[41]. Another problem is the unawareness of designers to develop older adults' applications [2] [12].

Accordingly, the purpose of this research is to measure older adults' competency to interact with smartphone screens, focusing on the vision of fonts and icons, hearing sounds, and touching on each key on the screen, and recognition. The tests and interviews were conducted and analyzed using comparative statistics to determine the older adults' competencies in controlling the devices, visualizing, hearing, tapping, and memorizing, and then applying the outcomes to the user interface design.

\section{Purpose and Research Method}

\section{$2.1 \quad$ Objective}

To measure the competencies to use mobile phones of the homebound older adults and apply them into application design.

\subsection{Participants}

The sample included old adults at the age of more than 60 who seldom go out, regardless of any reason. These old adults can still communicate without dementia and depression. Mini-mental State Examination (MMSE) and 9Q Depression Test, widely used according to the Thai normative guideline, were used to recruit the participants into the groups according to the study's inclusion criteria. All participants must possess smartphones and be able to access the internet. The participants were 26 in total: 5 males and 21 females. They lived in Sansuk Sub-district and nearby areas in Chonburi. All old participants had experience in using a smartphone for more than one year. Additionally, 23 participants $(88.46 \%)$ were right-handed. This study was approved by the Institutional Review Board (IRB) of Burapha University.

\subsection{Apparatus}

At the initial stage, it was found that 23 of 26 older adults (88.46\%) mostly used the Android operating system, which the screen size was around 5 inches. Therefore, Android OS on the Huawei Nova 2i smartphone was used to measure the competencies in using a homebound older adult's mobile phone. This model has a 5.9-inch screen, which was the standard screen size for older adults at a reasonable price. Most smartphones used by older adults in this area were not expensive, or they might obtain them from their offspring.

Designing the digital research tool was on the Android operating system for testing on competency in using smartphones. The test was designed based on older adults' 
physical impairments and mobile phone use. The digital research tool was validated by two experts and tested on five older people before being used to collect the actual data. It was divided into17 tests in 4 categories and implemented in Thai. Please see Table 1 for information on each section of the test.

Table 1. Test of homebound old adults' competency in using smartphones

\begin{tabular}{|l|c|l|}
\hline Categories & Amount & \multicolumn{1}{c|}{ Description } \\
\hline Vision & 6 & $\begin{array}{l}\text { To test participants' visual clarity on font style and size, as well as illustra- } \\
\text { tion or icon size on white and black background. }\end{array}$ \\
\hline Hearing & 1 & To test the participants' hearing in the real environment. \\
\hline Touching & 9 & $\begin{array}{l}\text { To detect touch, drag, and scroll in each position on the mobile screen, In- } \\
\text { cluding typing on the keyboard in all three sizes. Also, test about dragging } \\
\text { the chat screen. }\end{array}$ \\
\hline $\begin{array}{l}\text { Memoriz- } \\
\text { ing }\end{array}$ & 1 & $\begin{array}{l}\text { To test participants' short-term memory, memorize the } 6 \text { objects' locations } \\
\text { for } 1,2 \text {, and 3 seconds. }\end{array}$ \\
\hline
\end{tabular}

The system captured the screenshots in 1080*2160 pixel images (jpeg) before turning to the next test in each test. The recorded images and different values displayed on the screen were used for later analyses.

\subsection{Procedure}

Older adults performed their smartphones' competency on digital research instruments for testing their vision, hearing, touching, and recognition. Firstly, the appointment for the test was made with elderly participants in advance. The test was performed at their home. During the test, the elderly participants sat in a familiar and comfortable posture and listened to the tests' purposes and procedures being delivered by the researchers. In the test, older adults were required to conduct 17 tests in 4 categories(see table 2). They had to perform it without any help just only the instruction was given for each test, and the researchers were on standby in case they needed help. 
Table 2. Descriptions of 17 tests across 4 categories

\begin{tabular}{|c|c|c|}
\hline Categories & Test No. & Description \\
\hline \multirow[t]{6}{*}{ Vision } & 1 & $\begin{array}{l}\text { In this test, the older adults use a slider to adjust the font size and leadings, } \\
\text { which they can see most clearly. They have two options of fonts: Serif and } \\
\text { Sans Serif. }\end{array}$ \\
\hline & 2 & $\begin{array}{l}\text { After obtaining the font size results from the first test, this test is on contrast } \\
\text { ratio between black color on a white background to find older adults can } \\
\text { mostly see what color contrast. }\end{array}$ \\
\hline & 3 & $\begin{array}{l}\text { Continue testing the contrast ratio between white text color on black back- } \\
\text { ground. }\end{array}$ \\
\hline & 4 & $\begin{array}{l}\text { In this test, the older people select an icon format that is easily understood } \\
\text { from their perception, which consisted of Outlined, Flat, filled, Hand-drawn, } \\
\text { glyph, skeuomorphic and gradient style. }\end{array}$ \\
\hline & 5 & $\begin{array}{l}\text { After selecting the icon format, the older adults adjust the icon, which they } \\
\text { can see most clearly on the white background. The default is } 50 \mathrm{dp} \text {. }\end{array}$ \\
\hline & 6 & Continue testing the size of an icon on black background. \\
\hline Hearing & 7 & $\begin{array}{l}\text { This test is on the hearing competency of older adults. The test detects ambi- } \\
\text { ent sounds surrounding places where the elderly regularly use. Older adults } \\
\text { have to adjust the smartphone volume to the level they can hear most clearly } \\
\text { without annoyance or noisiness. }\end{array}$ \\
\hline \multirow[t]{5}{*}{ Touching } & $8-10$ & $\begin{array}{l}\text { This test is on touching the competency of older adults where they have to } \\
\text { perform by tapping on the buttons on the screen, which will have } 12 \text { square } \\
\text { buttons (size } 48 \mathrm{dp}, 72 \mathrm{dp} \text {, and } 96 \mathrm{dp} \text { in each test) align on the entire screen. } \\
\text { The system detects where they touch on the buttons and the total task time. }\end{array}$ \\
\hline & $11-13$ & $\begin{array}{l}\text { This test is similar to the preceding test, except the buttons change to a circu- } \\
\text { lar shape with } 48 \mathrm{dp}, 72 \mathrm{dp} \text {, and } 96 \mathrm{dp} \text { button diameter in each test. }\end{array}$ \\
\hline & 14 & $\begin{array}{l}\text { This test is on touching the buttons with the relationship between characters } \\
\text { and objects. The buttons' lengths are } 48 \mathrm{dp}, 72 \mathrm{dp} \text {, and } 96 \mathrm{dp} \text { to find where they } \\
\text { touch on the long buttons with text. }\end{array}$ \\
\hline & 15 & $\begin{array}{l}\text { This test is about sliding to the end of the screen. The researcher observes } \\
\text { their behaviors on holding the phone and the dragging location from the real } \\
\text { chatting screen situation. }\end{array}$ \\
\hline & 16 & $\begin{array}{l}\text { This test is about typing characters with } 3 \text { sizes of keyboards (extra small, } \\
\text { normal, and extra tall) to find the keyboard's appropriate size for typing cor- } \\
\text { rectly in a suitable typing time using a third-party application, google key- } \\
\text { board. }\end{array}$ \\
\hline Memorizing & 17 & $\begin{array}{l}\text { This test consists of } 3 \text { phases. In Phase } 1 \text {, the object appears in the table for } 1 \\
\text { second (Type } 1 \text { ), } 2 \text { seconds (Type } 2 \text { ), and } 3 \text { seconds (Type } 3 \text { ). The older } \\
\text { adults see the object for a moment according to the delay time setting. Then } \\
\text { they guess which box of the table contains the object. There are } 6 \text { objects for } \\
\text { the test, and the time is counted in each test until getting the response. }\end{array}$ \\
\hline
\end{tabular}

After the elderly completed the tests, the system immediately captured the screen for each test. Then, the researcher later obtained information and calculated the appropriate average scores and applied them to the mobile interface design.

\section{$3 \quad$ Literature Review}

Older adults now more than $60 \%$ of them have access to the internet[35]. The need for the internet has been increasing for searching, communicating, and accessing assisted technology[36]. Naturally, they do not buy their first phone, but social influence 
from children or younger people to buy or give to them[37]. They might feel it difficult to use for the first time. Touch screen interfaces now are influenced in every industry, such as care or machinery control systems. Many researchers develop usability and tools to help people to access touch screen technology easily[38].

Usability guideline for older adults on the touch screen has been done in many researches to test about font size, button size or even compared with the younger people[23][25][26][29][31][33]. The test results may vary due to the many devices, instruments, and factors used in the touch test. Moreover, most of them will test with the typical elderly. For example, some studies say optimal font size is 8-12 points[30], but in others, it is proposed at 22 points, which differs significantly[31], but in some research, avoid using speech recognition to avoid the touch[44].

As age increases, hand movements are associated with visual acuity. Blurred vision affects slow movements. Therefore, many studies have researched the size of buttons and characters, including icons that reduce responding time because larger screen size or button size can significantly decrease responding time and error[24]. It is like typing on a landscape's keyboard. It is more accurate and precise than portrait because of its larger key size. However, it should be minimized as possible because failure is high and often[28]. The size of the buttons is another matter that the researchers deem inappropriate. Some articles offer $15.9 * 9.0 \mathrm{~mm}$ to increase the performance[25]. In Android, the standard size is $48 * 48 \mathrm{dp}(7-10 \mathrm{~mm})$ [19], but Ketchaikosol[13] and Kingkarn[30] say $50 * 50$ pixels button is a suitable size for the elderly.

Some studies have addressed testing methods by clicking, dragging, zooming, and rotating on a touch screen[25]. As a result, it is known that the elderly are unable to perform well [24] and have a slow response due to the use of two hands and several fingers to control. Some studies have shown that generation and culture affect usability, and previous experiences with a computer are another factor affecting usage[24]. The problem of using the touch screen in the elderly can be divided into three significant implications. First, Physical deterioration problems with age, such as blurred vision, muscle weakness, hand trembling[24]. Second, Problems with the device itself, such as a small screen. The difference in the interface[42], the text is small. Unclear icons make it difficult for older adults to operate on the screen[34][41]. The theme of icon design and the interface is one that older people need to use their awareness and empathy to look at[41]. Skeuomorphic design, just like the practical use of everyday life, will make it easy to understand for older adults to understand[3][22], but robbin's research[20] has found that flat design works better in the middle-aged[4][5]. Moreover, younger adults can perform it more efficiently in skeuomorphic than flat design, but they prefer the flat design in terms of aesthetics [29]. Third, Older adults lack prior computer experience and their perception of privacy and trust. [33][34].They are unfamiliar with language and UI elements[41].

As per memory and perception, many researchers have tested, in terms of the psychological concepts such as Miller[8] and Broadbent[15]. Many studies tested and discussed the principles that should avoid using large amounts of data, deep hierarchies, display only the significance, and not allow the elderly to multitask[21]. Excessive use of memory, perception, and attention can lead to fatigue from work.That is why a simple, text-based interface is more effective for older people[26] because the abstractness 
and concreteness of icons or graphics are one variable in increasing or decreasing people's affordance and attention[27], but it was found out that the use of icon next to the text for a button can improve the affordance[28].

Due to the fact that there are several factors that there are many crucial factors in relating to the specific design. The given factors might include usage preferences, learning styles, lifestyles, cultural diversity. Furthermore, many previous studies solely focused and discussed on the design for typical older adults, however, there has been still rarely has investiaged in homebound older adults. It is expected that the current study would contribute by offering a different set of findings.

\section{$4 \quad$ Result and Discussion / Observation Finding}

In the digital test, the elderly participants' postures were observed during their smartphone use. Each participant sat and used the smartphones by using a non-dominant hand (left) to hold the smartphones and almost using only the middle fingers of the dominant hand (right) to touch the screen (cradling in two hands). With this posture, the users could touch the keys or screen freely [16].

\subsection{Vision}

In the vision test with Thai font, $84.62 \%$ of the elderly participants preferred the Serif font type because it was easy to read. The suitable font size was at the average of $17 \mathrm{pt}(16.77 \mathrm{pt})$ or in the physical size at about $4 \mathrm{~mm}$ by measuring from the screen. The font size was similar to Ellen Lution's suggestion that characters should be between 14-18 pt [6]. Maneerat and Helen's studies found that 18pt is the best view, and it increases the reading speed by using a serif font for thai typeface[32]. However, it is different from Iancu's and other [7][30] suggestions at 12 pt. Regarding the space between lines, the elderly participants suggested that the average was suitable and set as the standard default.

The contrast is the other issue that should be aware of the vision. Lack of contrast could impact user with older adults' low vision[34]. Using the contrast color helps older adults easily see the object[43]. In the character color contrast and background test, the elderly participants adjusted the characters' color, which made them see the characters best easily and comfortably on the dark and light backgrounds.

- The elderly participants could see the character color clearly on the white background at the average vision of 7.18:1.

- The elderly participants could see the character color clearly on the black background at the average vision of 8.63:1.

WCAG (Web Content Accessibility Guidelines) suggests the minimum contrast at 4.5: 1, but if the characters are very large, 3:1 is suggested for clear vision. However, these elderly participants preferred more color contrast for easy and comfortable reading. 
Table 3. Result and Contribution about font

\begin{tabular}{|l|l|l|}
\hline \multicolumn{1}{|c|}{ Test no. } & \multicolumn{1}{|c|}{ Result } & \multicolumn{1}{c|}{ Contribution } \\
\hline $\begin{array}{l}\text { Font style/Font } \\
\text { size / Leading }\end{array}$ & $\begin{array}{l}\text { Serif/16.77pt } \\
\text { /default }\end{array}$ & $\begin{array}{l}\text { Font style, font size, and Leading can be used in websites or applications } \\
\text { design to increase the quality of reading and reduce visual fatigue and at- } \\
\text { tention. }\end{array}$ \\
\hline $\begin{array}{l}\text { Contrast ratio on } \\
\text { white back- } \\
\text { ground }\end{array}$ & $7.18: 1$ & $\begin{array}{l}\text { Suitable Contrast Ratio Value can be applied to manipulate the visual acu- } \\
\text { ity, which will allow the older adults to discern objects, buttons, illustra- } \\
\text { tions, including letters that will make them easy to read on a bright back- } \\
\text { ground. }\end{array}$ \\
\hline $\begin{array}{l}\text { Contrast ratio on } \\
\text { black } \\
\text { background }\end{array}$ & $8.63: 1$ & $\begin{array}{l}\text { Suitable Contrast Ratio Value can be applied to manipulate the visual acu- } \\
\text { ity, which will allow the older adults to discern objects, buttons, illustra- } \\
\text { tions, including letters that will make them easy to read on a dark back- } \\
\text { ground. }\end{array}$ \\
\hline
\end{tabular}

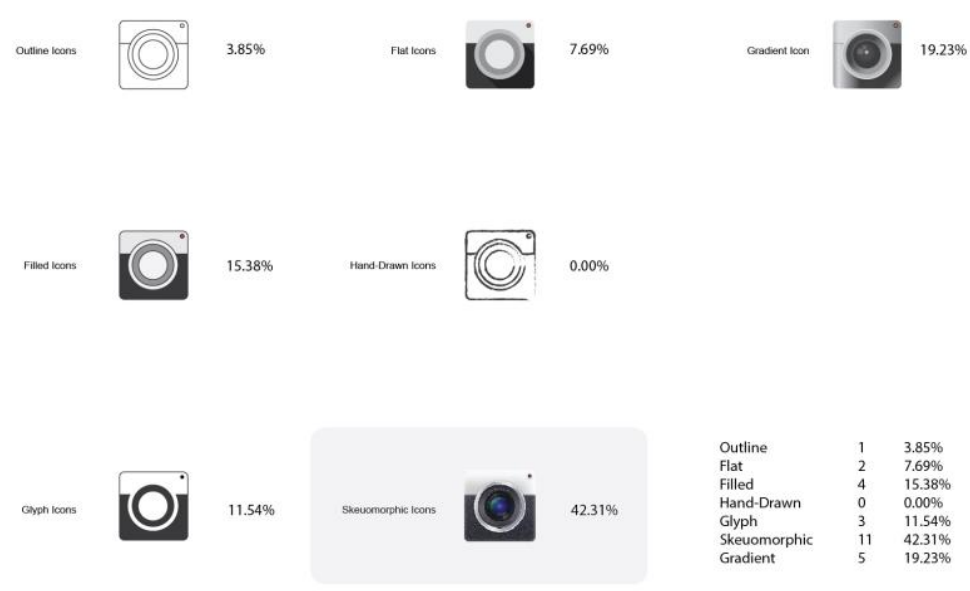

Fig. 1. Icon format for the elderly participants' easy understanding

According to Figure 1 about the icon format, the elderly participants could recognize and understand the skeuomorphic format more than other formats $(42.31 \%)$, followed by the gradient format $(19.23 \%)$, so the skeuomorphic format could communicate well with effective recognition by the elderly participants [3][22][29]. The interface of skeuomorphic format and flat design was tested that enabled elderly users to use the phone quickly with more accuracy than flat design. Flat design could work well with and was preferred by young children [4] [5] [20][29]. Regarding the suitable icon size for the clear vision of elderly people, the participants were asked to adjust the icon size on dark and light backgrounds. The icon sizes were slightly different. The icon on the dark background was larger than on the white background at about 17 pixels. This difference is little without significance, as stated by Pedersen in User Interfaces in Dark Mode During Daytime - Improved Productivity or Just Cool-Looking?, in the test of typing on black and white keyboards [9]. However, several research showed that vision on dark mode is more effective. 
- The average icon size on the white background was at 173.31 pixels for the elderly people's good recognition.

- The average icon size on the black background was at 190.58 pixels for the elderly people's good recognition.

Table 4. Result and Contribution about icon

\begin{tabular}{|l|l|l|}
\hline \multicolumn{1}{|c|}{ Test no. } & \multicolumn{1}{|c|}{ Result } & \multicolumn{1}{c|}{ Contribution } \\
\hline Icon style & Skeuomorphic & $\begin{array}{l}\text { Can adopt a Skeuomorphic style then applied in the interface design } \\
\text { for easy understanding of the older adults. }\end{array}$ \\
\hline $\begin{array}{l}\text { Icon size on the } \\
\text { white background }\end{array}$ & $173.37 \mathrm{px}$ & $\begin{array}{l}\text { The size can be applied to the size of illustrations and icons on a bright } \\
\text { background. }\end{array}$ \\
\hline $\begin{array}{l}\text { Icon size on the } \\
\text { black background }\end{array}$ & $190.58 \mathrm{px}$ & $\begin{array}{l}\text { The size can be applied to the size of illustrations and icons on a dark } \\
\text { background. }\end{array}$ \\
\hline
\end{tabular}

\subsection{Hearing}

Aging reduces hearing competency. When the age reaches more than 60 , the hearing ability will be reduced by $25 \%$. The ability to hear low noise is difficult and ability to differentiate noise reduces [18]. In the test of hearing competency, ambient sound or sound surrounding the elderly residence was detected. The participants adjusted the sound in a 0-100 range for which level was the most clearly audible level to listen to the radio podcast. Then the obtained results were compared to find the average for balancing the hearing sound.

The average volume adjusted by the elderly participants was at 68 from 100 or about 70.65 decibels, whereas the ambient sound was at 51.46 decibels. The hearing sound was louder than the ambient sound at about 37.29 percent.

When working with the sound for older adults, the result of average ambient and adjustment volume can be applied to the sound system by automatically tuning and adjusting it louder or softer according to the ambient sounds by using different percentage (37.29\%).

\subsection{Touching / Interaction}

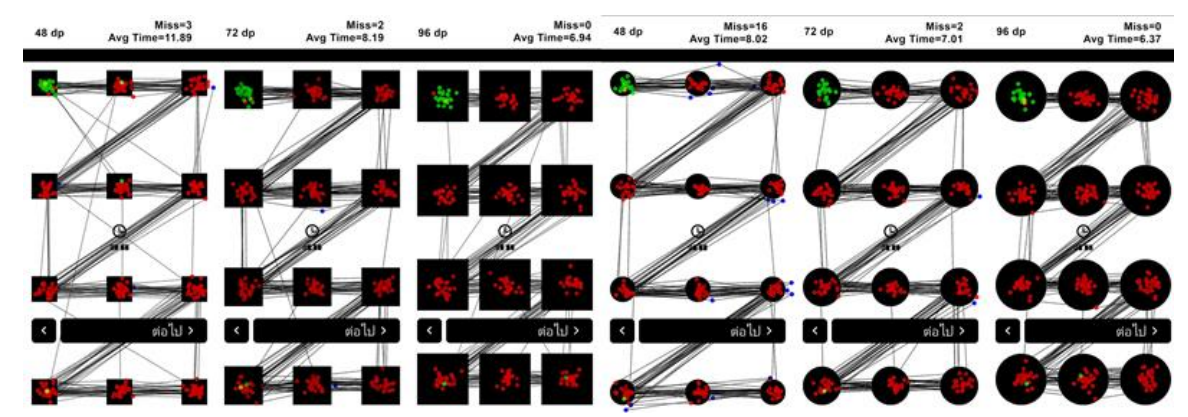

Fig. 2. The average value of operation and touching points on different size of buttons 
Figure 2 shows the interaction with 3 sizes of square keys. The elderly participants used the standard key size of $48 \mathrm{dp}(9 \mathrm{~mm})$ with 3 errors, but they used the 1-fold larger key size or $96 \mathrm{dp}(17 \mathrm{~mm})$ without errors in a noticeably reduced operation time. This result was different from the result in Ellen Lupton's [6] study, which proposed the physical size of $8 \mathrm{~mm}$ whereas Ketchaikosol and Kingkarn suggested the suitable size at about 50px [13][30]. The thumb interaction has been proposed to use 44 pixels for the thumb[34]. In this study, the operation time reduced clearly and considerably, conforming to Fitt's Law, which states that interaction time depends on distance and object size [12]. Tapping in the smaller buttons can cause fatigue slowly and slower than the large buttons[40].

Regarding the touching points on 48 and $72 \mathrm{dp}$ size, the elderly participants' touching was observed on the middle point slightly tilting to the right on the lower right of the key. However, with the larger keys of $96 \mathrm{dpi}$, the elderly touching was clustered in the middle without errors in clearly reduced operation time.

In the touching test of the circle keys, there were 16 errors with the small keys (48 dp), 2 errors with the medium keys ( $72 \mathrm{dp}$ ), and no errors with the large keys. However, it was surprising that the touching on the small circle keys was quicker than that on the square keys at 3.82 seconds, and the touching on the medium keys was also quicker at 1.18 seconds. The operation time for touching on the large keys was slightly different $(0.57 \mathrm{~s})$. On the other hand, the rectangle button is more accurate. It was assumed that the touching on the circle shape was quicker than the square shape, so the circle was more user-friendly for the elderly participants freely touch than the square, so that the round corner rectangle might be the answer for the shape of the button.

Table 5. The average time on touching 1 key (millisecond)

\begin{tabular}{|l|c|c|c|}
\hline \multicolumn{1}{|c|}{ Size } & 48dp (9mm) & 72dp (13mm) & 96dp (17mm) \\
\hline Square & $0.99 \mathrm{~ms}$ & $0.68 \mathrm{~ms}$ & $0.57 \mathrm{~ms}$ \\
\hline Circle & $0.66 \mathrm{~ms}$ & $0.58 \mathrm{~ms}$ & $0.53 \mathrm{~ms}$ \\
\hline Average time of both shapes & $0.82 \mathrm{~ms}$ & $0.63 \mathrm{~ms}$ & $0.55 \mathrm{~ms}$ \\
\hline
\end{tabular}

From observing the touching test with the square and circle keys, it could be concluded that the large keys could work effectively and suitably for elderly users with reduction of errors in operation (100\%), reduction of operation with quick key touching. The average touching time on each $96 \mathrm{dp}$ key, both in square and circle shapes, was at about 0.55 seconds, as shown in Table 5 . 


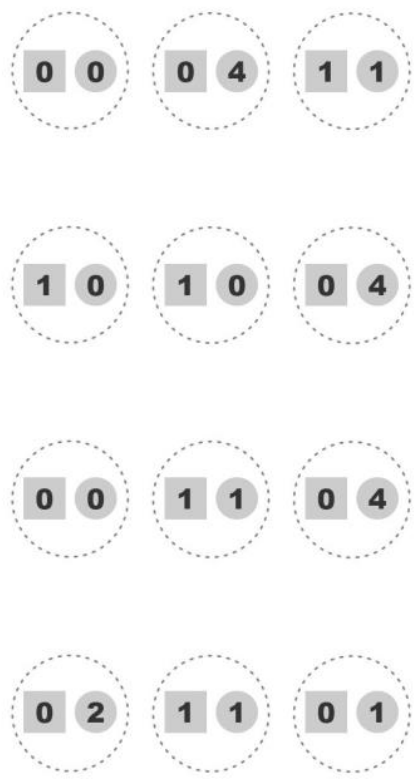

Fig. 3. The number of errors on touching each key in each position on the screen

The direction of the tested key touching shown in Figure 2, the most elderly participants (84.62\% or 22 of 26 people) likely touched the keys on the upper left to the right and move from left to right as in their normal reading with the end at the lower right. However, only a small number of them (15.38\% or 4 of 26 people) touched the key differently with the starting and ending points, similar to Gutenberg's theory[39]. This theory states that the primary optical area is the first part of the first sight or a distinctive point, and then the eyes sweep from the upper left diagonal to end at the lower right. Another observation was that these two points were the points with less occurrence of errors than the other points on the screen, as shown in Figure 3. In Po-Chan's experiment, the buttons at the top position are best used for older adults. On the other hand, the buttons on the left work the worst[31]. This research revealed that the screen's right hand's address button has more errors than the left one.

Fig. 4. The touching point on the keys with different lengths

According to the touching test on the short, medium, and long buttons on the phone screen, as shown in Figure 4, it was observed that all elderly participants touched only in the central point, slightly tilting to the right or only on the characters. In one study, if an icon was included, older people were more likely to press on the icon than on the text[28]. It can be interpreted that their right hands are dominant hands for touching and operation, so it is affected to where the user taps to the button. Perhaps, it was not 
necessary to use the long button keys. However, the length helped avoid an error when touching.

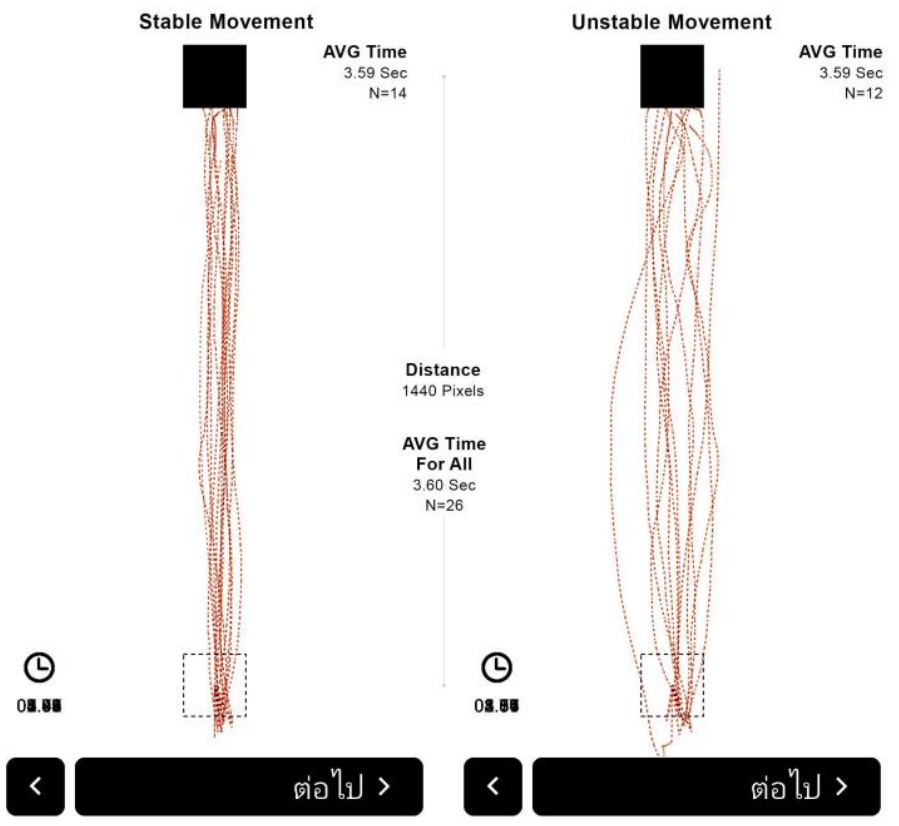

Fig. 5. Result in Dragging test

Regarding dragging objects, $46.15 \%$ of the elderly participants could not make stable finger movements to drag objects, as illustrated in Figure 5. The cause might be aging, physical impairment by age, or diseases. They might not be familiar with this interaction because it requires the user to keep pressing until they finish the task[41]. Although all elderly participants could successfully do this task, it was interesting that the participants who dragged with stable and unstable movements took the same average dragging time of 3.59 seconds in a 1440-pixel distance [11]. From this test, it can be interpreted that dragging an object or any elements on a mobile screen is not suitable for older adults. They might get some difficulties doing the task because half of them cannot perform it expertly. 


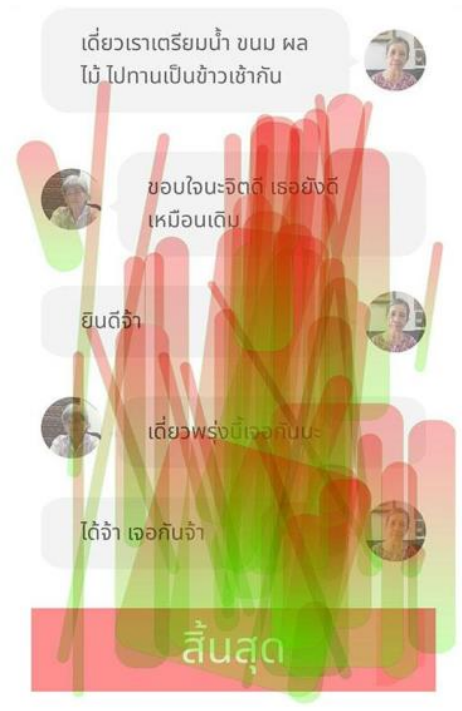

\section{ต่อไป >}

Fig. 6. The touching points of dragging on screen to read texts

From figure 4, the posture could affect interaction on the mobile screen. Therefore this test simulates a chatting screen for older adults to perform dragging on the screen to read texts. The researchers illustrate the dragging line in Figure 6 to represent the most frequent touching areas' density. Green represents the starting of dragging points, whereas red represents the end of it. This test informs us about the positions where the elderly users frequently touch to avoid placing essential keys in that area while sliding display and using the data to design objects or main action buttons on display without any sliding.

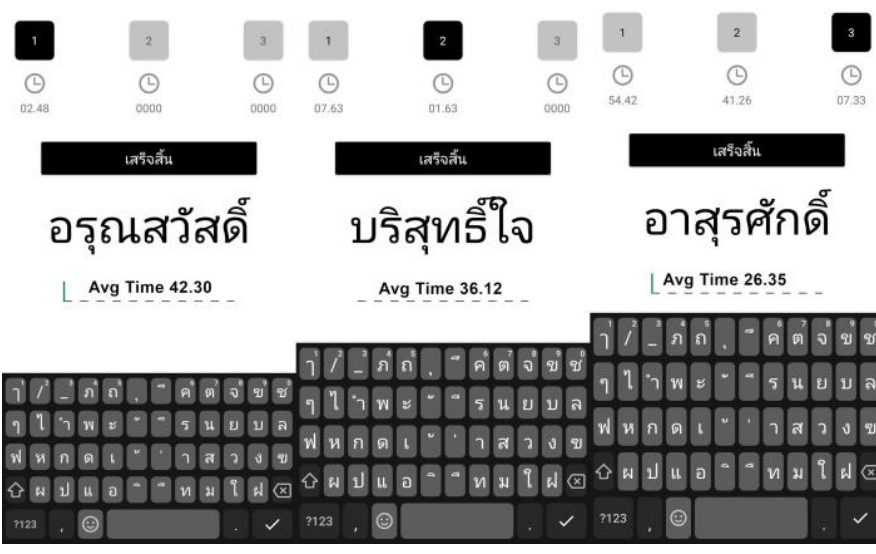

Fig. 7. Typing Exercise 
Figure 7 illustrates the typing test on the phone screen by using three types of Google keyboards: Extra Short with a physical height of $39 \mathrm{~mm}$ (about 627 pixels), Normal with a physical height of $46 \mathrm{~mm}$ (about 739 pixels), and Extra Tall with a physical height of $52 \mathrm{~mm}$ (about 847 pixels). Words used for the typing test were not the same, but they are in similar form with the same numbers of consonants and vowels and the same number of using shift keys to avoid getting familiar with typing the same words.

According to the test, the larger the keyboard was, the more accurately and quickly the typing was. The use of the large keyboard is quicker in operation than the small keyboard at $62.29 \%$. During the test, most elderly participants often made spelling errors. Only a few of them could use it competently. In this test, 2 participants were unable to use the keyboard.

\subsection{Memorizing // Short-term memory test}

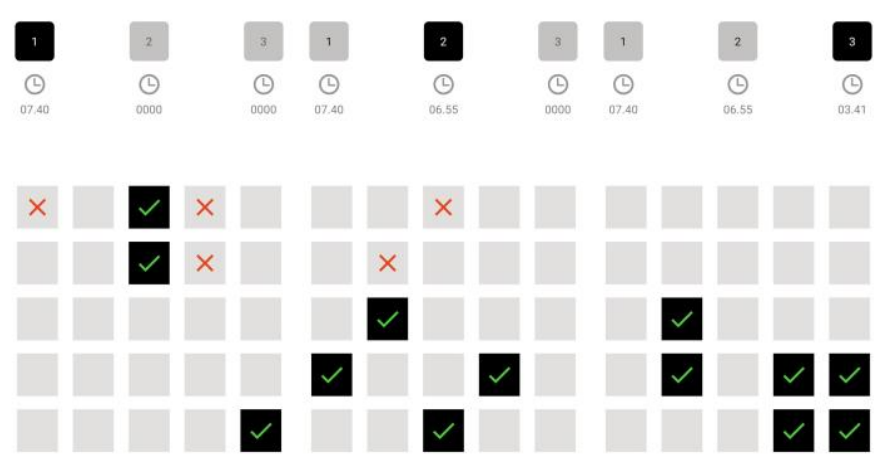

Fig. 8. Short-Term Memory Test

Figure 8 shows a short-term memory test. The testing results were different from Miller's Law, which states that general people can remember seven items simultaneously [8]. In this test, however, objects were presented to the participants for 1 second, 2 seconds, and 3 seconds respectively; and the results revealed the average recall of $4.19-4.5$ items. This result is similar to Broadbent's test on four-plus or minus 1 [15].

Table 6. The average time and accuracy in the short-term memory test

\begin{tabular}{|l|c|c|c|}
\hline & Exercise1: 1 Sec & Exercise 2: 2 Sec & Exercise3: 3 Sec \\
\hline Avg Time $(\mathrm{Sec})$ & 9.36 & 7.26 & 7.66 \\
\hline Average Correctness & 4.19 from $6(69.83 \%)$ & 4.46 from $6(74.33 \%)$ & 4.50 from $6(75 \%)$ \\
\hline
\end{tabular}


Older adults usually have a short-term recall, which will be a little better if they see the objects longer. Table 6 shows that seeing the objects for 1 second and 3 seconds. The average time to complete the task is different significantly. It reduces from 9.36 to 7.66 seconds. On the other hand, the average correctness is increased. This test is revealed that The error rate will be decreased if participants use more time on the task, but if the memory load is reduced, the error and less time consumed rate will be decreased.

The researchers observed that the difficulty level of the test (the number and positions of the randomized objects) was an important factor affecting the elderly participants. Similarly, seeing time was also another factor. Seeing objects for 2 seconds and 3 seconds was not much different, which might be due to the participants' concentration or reasonable recall rate at 2 seconds. Therefore, the smartphone should be designed to reduce cognitive loads for older adults in order to recall more easily and quickly. Reducing things to remember can decrease error and time consumed.

\section{Conclusion}

Physical impairment is the main obstacle against the smartphone use of older adults. According to each test in the current study, the elderly participants demonstrated different needs. They had less competency in using smartphones than typical older adults, such as bigger font size, icon size, button size, unstable dragging movement, and touching pattern in every screen position. The best optimal font face that works well with older adults' eyes could be Serif, around 17-18 pt. The contrast ratio between the text and light background should be more than 7.16:1, but on a dark background was 8.63:1. The more prominent button at 96dp could increase the speed and reduce responding time. The circle button seemed to be reduced responding time more than the rectangle, but the rectangle button was more accurate so that the round corner rectangle might be the answer for the shape of the button. The button test's length with the letter could be revealed that we properly did not require a long button because users always tapped in the center or on the letter only. The button on the right edge of the screen could increase the interaction's error. An ambient sound that we discovered and measured from older adults' homes is $51.46 \mathrm{db}$, so the satisfying sound level that older adults adjusted was around $71 \mathrm{db}$ (37\% difference). From the dragging test, almost half of the older adults could not perform a stable dragging movement, but they could slowly complete the task. Typing was also another obstacle, but older adults could perform it better with a large keyboard(Extra tall) but made many mistakes. The best average score of memory by remembering the object's position was around 4.5 items at 3 seconds in terms of memory span. When older adults spent more time, the error rate could be reduced, but it came with the time consumed or interaction time.

The significant contribution of the current study may relate to older adults' quality of life and to the senior community. The main findings of this study will provide the optimal variables to the specific designs for homebound older adults in terms of the average size of the font, icon, decibel, and how they interact with the touch screen. This result will also improve the usability among older adults. Due to the intuitive usability, 
older adults can easily access the assisted technology and have more confidence to use them. This result can also be a useful guideline and recommendation for every designer who plans to design touchscreen technology to assist all older adults. The current experiment can be applied in further research to create the best touch screen interface for homebound older adults and test their tangible satisfaction by using physiological devices (e.g. electroencephalography, functional magnetic resonance imaging). However, these tests were only examined on the android user. The outcome may be different if it is on other platforms or operating systems. It could also test on the other positions or different situations such as standing or doing some activity because this test is only tested on the convenient posture.

\section{References}

[1] National Statistical Office, The 2018 Household Survey on the Use of Information and Communication Technology (Quarter 1). National Statistical Office, 2018.

[2] W. C. W. A. I. (WAI), "Older Users and Web Accessibility: Meeting the Needs of Ageing Web Users," Web Accessibility Initiative (WAI), 02-Nov-2020. [Online]. Available: https://www.w3.org/WAI/older-users/. [Accessed: 03-Nov-2020]. https://doi.org/10.1145/ 2187980.2188012

[3] M. Cho, S. Kwon, N. Na, H.-J. Suk, and K. Lee, "The Elders Preference for Skeuomorphism as App Icon Style," Proceedings of the 33rd Annual ACM Conference Extended Abstracts on Human Factors in Computing Systems - CHI EA '15, 2015. https://doi.org/10.1145/ 2702613.2732887

[4] I. C. V. P. Urbano, J. P. V. Guerreiro, and H. M. A. A. Nicolau, "From skeuomorphism to flat design: age-related differences in performance and aesthetic perceptions," Behaviour \& Information Technology, pp. 1-16, 2020. https://doi.org/10.1080/0144929x.2020.1814867

[5] N. Backhaus, A. K. Trapp, and M. Thüring, "Skeuomorph Versus Flat Design: User Experience and Age-Related Preferences," Design, User Experience, and Usability: Designing Interactions Lecture Notes in Computer Science, pp. 527-542, 2018. https://doi.org/10.1007 1978-3-319-91803-7 40

[6] E. Lupton, Type on screen: a guide for designers, developers, writers, and students. NY, NY: Princeton Architectural Press, 2014.

[7] I. Iancu and B. Iancu, "Elderly in the Digital Era. Theoretical Perspectives on Assistive Technologies," Technologies, vol. 5, no. 3, p. 60, 2017. https://doi.org/10.3390/ technologies 5030060

[8] J. E. F. F. Johnson, Designing With the Mind in Mind: Simple Guide to Understanding User interface Design Guidelines. Place of publication not identified: Morgan Kaufmann Publisher, 2020.

[9] L. A. Pedersen, S. S. Einarsson, F. A. Rikheim, and F. E. Sandnes, "User Interfaces in Dark Mode During Daytime - Improved Productivity or Just Cool-Looking?," Lecture Notes in Computer Science Universal Access in Human-Computer Interaction. Design Approaches and Supporting Technologies, pp. 178-187, 2020. https://doi.org/10.1007/978-3-030$\underline{49282-3 \_13}$

[10] M. Kobayashi, A. Hiyama, T. Miura, C. Asakawa, M. Hirose, and T. Ifukube, "Elderly User Evaluation of Mobile Touchscreen Interactions," Human-Computer Interaction INTERACT 2011 Lecture Notes in Computer Science, pp. 83-99, 2011. https://doi.org/10. 1007/978-3-642-23774-4_9 
[11] O. Campbell, "Designing For The Elderly: Ways Older People Use Digital Technology Differently," Smashing Magazine, 05-Feb-2015. [Online]. Available: https://www.smashingmagazine.com/2015/02/designing-digital-technology-for-the-elderly/. [Accessed: 02-Nov2020].

[12] S. Hoober and E. Berkman, Designing mobile interfaces. O'Reilly, 2012.

[13] V. Ketchaikosol, "A Study of Action-Button Size on Mobile Applications for Elderly," dissertation, 2016.

[14] The World Wide Web Consortium, "Understanding Success Criterion 1.4.3: Contrast (Minimum)," Understanding Success Criterion 1.4.3: Contrast (Minimum), 2016. [Online]. Available: https://www.w3.org/WAI/WCAG21/Understanding/contrast-minimum.html. [Accessed: 02-Nov-2020].

[15] D. E. Broadbent, "Cognitive Psychology And Education," British Journal of Educational Psychology, vol. 45, no. 2, pp. 162-176, 1975. https://doi.org/10.1111/j.2044-8279.1975. $\underline{\text { tb03241.x }}$

[16] S. Hoober, "How Do Users Really Hold Mobile Devices?," UXmatters, 18-Feb-2013. [Online]. Available: https://www.uxmatters.com/mt/archives/2013/02/how-do-users-reallyhold-mobile-devices.php. [Accessed: 04-Nov-2020].

[17] Changporn Konma, "Sansuk Smart City, a smart city that uses technology to improve quality of life for the elderly," 06-Jan-2020. [Online]. Available: https://readthecloud.co/sansooksmart-city-chon-buri/. [Accessed: 27-Nov-2020].

[18] J. Johnson and K. Finn, Designing user interfaces for an aging population: towards universal design. Cambridge: Morgan Kaufmann, 2017.

[19] Google, "Touch target size - Android Accessibility Help," Google. [Online]. Available: https://support.google.com/accessibility/android/answer/7101858?hl=en. [Accessed: 04Feb-2021].

[20] W. H. Robbins, thesis, California Polytechnic State University, 2014.

[21] S. Carmien and A. G. Manzanares, "Elders Using Smartphones - A Set of Research Based Heuristic Guidelines for Designers," Lecture Notes in Computer Science, pp. 26-37, 2014. https://doi.org/10.1007/978-3-319-07440-5_3

[22] M. Cho, S. Kwon, N. Na, H.-J. Suk, and K. P. Lee, "The Elders Preference for Skeuomorphism as App Icon Style," Proceedings of the 33rd Annual ACM Conference Extended Abstracts on Human Factors in Computing Systems, 2015. https://doi.org/10.1145/ 2702613.2732887

[23] J. Zhou, P.-L. P. Rau, and G. Salvendy, "Age-related difference in the use of mobile phones," Universal Access in the Information Society, vol. 13, no. 4, pp. 401-413. https://doi.org/ 10.1007/s10209-013-0324-1

[24] W. Lin, H.-C. Lin, and H.-P. Yueh, "Explore Elder Users' Reading Behaviors with Online Newspaper," Cross-Cultural Design, pp. 184-192, 2014. https://doi.org/10.1007/978-3319-07308-8_18

[25] Q. Gao and Q. Sun, "Examining the Usability of Touch Screen Gestures for Older and Younger Adults," Human Factors: The Journal of the Human Factors and Ergonomics Society, vol. 57, no. 5, 2015. https://doi.org/10.1177/0018720815581293

[26] G. R. Reddy, A. Blackler, V. Popovic, M. H. Thompson, and D. Mahar, "The effects of redundancy in user-interface design on older users," International Journal of Human-Computer Studies, 2020. https://doi.org/10.1016/j.ijhcs.2019.102385

[27] S.-W. Hsiao, C.-H. Lee, M.-H. Yang, and R.-Q. Chen, "User interface based on natural interaction design for seniors," Computers in Human Behavior, vol. 75, 2017. https://doi.org/ $\underline{\text { 10.1016/j.chb.2017.05.011 }}$ 
[28] A. C. de Barros, R. Leitão, and J. Ribeiro, "Design and Evaluation of a Mobile User Interface for Older Adults: Navigation, Interaction and Visual Design Recommendations," Procedia Computer Science, vol. 27, pp. 369-378, 2014. https://doi.org/10.1016/j.procs.2014.02.041

[29] R. Chen, J. Huang, and J. Zhou, "Skeuomorphic or flat icons for an efficient visual search by younger and older adults?," Applied Ergonomics, vol. 85, 2020. https://doi.org/10. 1016/j.apergo.2020.103073

[30] K. Sookhanaphibarn, V. Ketchaikosoal, and C. Kanjanayothin, "Optimum button size and reading character size on mobile user interface for Thai elderly people," 2017 IEEE 6th Global Conference on Consumer Electronics (GCCE), 2017. https://doi.org/10.1109/gcce. $\underline{2017.8229479}$

[31] P.-C. Yeh, "Impact of button position and touchscreen font size on healthcare device operation by older adults," Heliyon, vol. 6, no. 6, 2020. https://doi.org/10.1016 j.heliyon.2020.e04147

[32] M. Chatrangsan and H. Petrie, "The effect of typeface and font size on reading text on a tablet computer for older and younger people," Proceedings of the 16th Web For All 2019 Personalization - Personalizing the Web, 2019. https://doi.org/10.1145/3315002.3317568

[33] K. Krayz Allah, N. A. Ismail, and M. Almgerbi, "Designing web search UI for the elderly community: a systematic literature review," Journal of Ambient Intelligence and Humanized Computing, 2021. https://doi.org/10.1007/s12652-020-02772-8

[34] J. Arfaa and Y. Wang, "Elder Adults Utilizing Social Networking Sites on Mobile Platforms," Human Aspects of IT for the Aged Population. Healthy and Active Aging, pp. 167175, 2016. https://doi.org/10.1007/978-3-319-39949-2_16

[35] C. Romanyk, R. McCallum, and P. Salehi, "A Model Based Approach to Web Application Design for Older Adults Using MVC Design Pattern," Human Aspects of IT for the Aged Population. Healthy and Active Aging, pp. 348-357, 2016. https://doi.org/10.1007/978-3$\underline{319-39399-5 \_33}$

[36] K. Krayz Allah, N. A. Ismail, and M. Almgerbi, "Designing web search UI for the elderly community: a systematic literature review," Journal of Ambient Intelligence and Humanized Computing, 2021. https://doi.org/10.1007/s12652-020-02772-8

[37] S. Oppl and C. Stary, "Game-playing as an effective learning resource for elderly people: encouraging experiential adoption of touchscreen technologies," Universal Access in the Information Society, vol. 19, no. 2, pp. 295-310, 2018. https://doi.org/10.1007/s10209-018$\underline{0638-0}$

[38] A. Colley, L. Virtanen, T. Ojala, and J. Häkkilä, “Guided touch screen," Proceedings of the 5th ACM International Symposium on Pervasive Displays, 2016. https://doi.org/10.1145/ 2914920.2915008

[39] W. L. K. H. \& J. Butler., Universal Principles of Design, Revised and Updated: 125 Ways to Enhance Usability, Influence Perception, Increase Appeal, Make Better Design Decisions, and Teach through Design. 2012. https://doi.org/10.1075/idj.14.2.11byr

[40] J. Xiong and S. Muraki, "Thumb performance of elderly users on smartphone touchscreen," SpringerPlus, vol. 5, no. 1, 2016. https://doi.org/10.1186/s40064-016-2877-y

[41] H. M. Salman, W. F. Wan Ahmad, and S. Sulaiman, "Usability Evaluation of the Smartphone User Interface in Supporting Elderly Users From Experts' Perspective," IEEE Access, vol. 6, pp. 22578-22591, 2018. https://doi.org/10.1109/access.2018.2827358

[42] M. A. Saare, A. Hussain, and W. Seng Yue, "Investigating the effectiveness of mobile peer support to enhance the quality of life of older adults: A systematic literature review," International Journal of Interactive Mobile Technologies (iJIM), vol. 13, no. 04, p. 130, 2019. https://doi.org/10.3991/ijim.v13i04.10525 
[43] L. L. Sie-Yi and N. ChePa, "Criteria of Mobile Psychotherapy Games for Memory Disorder: A Systematic Literature Review," International Journal of Interactive Mobile Technologies (iJIM), vol. 14, no. 05, p. 57, 2020. https://doi.org/10.3991/ijim.v14i05.13345

[44] S. Nuanmeesri, "Mobile Application Development of Managing Elderly Household Accounts Using Speech Recognition," International Journal of Interactive Mobile Technologies (iJIM), vol. 14, no. 02, p. 84, 2020. https://doi.org/10.3991/ijim.v14i02.11651

\section{$7 \quad$ Authors}

Patana Duangpatra is a full-time lecturer at the Faculty of Albert Laurence School of Communication Arts, Department of Digital Media, Assumption University. He is a PhD candidate in Doctor of Philosophy, Major in visual arts, and Design, Burapha University, Thailand. He often works as a UI and UX designer.

Asst. Prof. Bunchoo Bunlikhitsiri, Ph.D., is associate dean of the Faculty of Fine and Applied Art, Burapha University, Thailand. He works in the digital media field and currently working on a Visual reality project.

Peera Wongupparaj, Ph.D., is assistant dean of College of Research Methodology and Cognitive Science, Burapha University, Thailand. He always works and researches with other international Universities regarding Neuroscience and Cognitive Psychology.

Article submitted 2021-01-03. Resubmitted 2021-02-26. Final acceptance 2021-02-26. Final version published as submitted by the authors. 